\title{
Prevalence and pattern of cognitive impairment in rural and urban populations from Northern Portugal
}

\author{
Belina Nunes 1,2, Ricardo D Silva², Vitor T Cruz²,3, Jose M Roriz1 , Joana Pais2,4 and Maria C Silva*5
}

\begin{abstract}
Background: Despite worldwide recognition of the burden of dementia, no epidemiological data is yet available in Portugal. The objective of this study is to estimate the prevalence and describe the pattern of cognitive impairment with dementia or no dementia (CIND) in rural and urban populations from Northern Portugal.

Methods: Two random samples of residents aged 55 to 79 years in rural and urban communities were drawn from the health centres registries to be screened for cognitive impairment. The screening criteria for dementia were an abnormal Mini-Mental State Examination (MMSE) score or a Blessed Dementia Scale score. After excluding those who tested positive for dementia, cut-off points for CIND were set at 1 standard deviation below the mean of the MMSE according to educational level. All those who screened positive either for dementia or CIND were examined by a neurologist for establishing a definitive diagnosis.
\end{abstract}

Results: The prevalence of cognitive impairment was higher in rural than in urban populations, $16.8 \%$ (95\% Cl: 14.3$19.8 \%$ ) vs. $12.0 \%$ (95\%Cl: 9.3-15.4\%), with a rural/urban prevalence ratio (PR) of 2.16 (95\% Cl: 1.04-4.50) in the eldest and 2.19 (95\% Cl: 1.01-4.76) in persons with vascular risk factors. The prevalence of dementia was $2.7 \%$ (95\% Cl: 1.9-3.8\%) with a rural/urban $P R=2.1$ and the prevalence of CIND was $12.3 \%(95 \% \mathrm{Cl}: 10.4-14.4 \%)$ and $P R=1.3$. The prevalence of dementia increases exponentially with age and in those with cerebrovascular disease or other comorbid conditions while the prevalence of CIND, besides these factors, is also higher in persons with low levels of education or vascular risk factors. Alzheimer's and vascular disease were equally likely aetiologies of dementia (38.7\%), the later more common in men PR(F:M = 0.3) as opposed to the former PR(F:M = 2.0). Vascular CIND, associated either with cerebrovascular disease or vascular risk factors was more frequent (39.7\%) then depression (18.4\%) or any other aetiology.

Conclusions: The prevalence of cognitive impairment is higher in rural compared with urban populations. This is shown in the synergy between age and rurality, with the rural/urban prevalence ratio increasing with age. In this relatively young population from Northern Portugal, cerebrovascular disease as well as vascular risk factors account for $48 \%$ of overall cognitive impairment.

\section{Background}

Dementia, as defined by the American Psychiatric Association's 4th revision of the Diagnostic and Statistic Manual of Mental Disorders (DSM-IV-TR), is characterized by the presence of cognitive deficits over multiple domains, including memory and at least another - aphasia, apraxia, agnosia or executive functioning disturbance

* Correspondence: carolina@icbas.up.pt

5 UNIFAI, Instituto de Ciências Biomêdicas Abel Salazar (ICBAS), University of Porto, 4099-003, Porto, Portugal

Full list of author information is available at the end of the article
- which should represent a deterioration from a previously better level of functioning, exceeding what would be reasonably expectable for normal aging, and be severe enough to compromise the subject's occupational and social skills [1]. Although not essential for diagnosis, several other cognitive domains can be variably affected - as disturbances of visual-spatial processing, insight, critical judgement, attention or social inhibition, perceptual or self neglect, aggressiveness and behavioural changes, humour and sleep disturbances, anxiety, delusions and 
hallucinations, motor or gait disturbances, etc. - and the diagnosis must be withheld if the cognitive deficits are known to occur exclusively in the dependence of delirium/acute confusional states or a major depressive disorder. Accordingly, not all cognitively impaired people have dementia, and a number of concepts have been proposed to describe the transitional states between cognitive integrity, subjective memory complaints, physiological mental aging and dementia. 'Cognitive impairment no dementia' (CIND) is perhaps the most comprehensive and unifying, by merely including all persons suffering from cognitive disturbances not severe enough to satisfy the diagnostic criteria for dementia [2,3].

Understanding the epidemiology of dementia and CIND in a given population is crucial for an adequate planning of public health strategies and rational allocation of resources. However, given the lack of epidemiological data on dementia in Portugal, the number of affected persons has been calculated using prevalence estimates in other European countries [4,5], which may not reflect the patterns of disease in our country. For instance, stroke and TIA incidences in rural northern Portugal are known to rank among the highest reported in community-based studies [6,7], probably resulting from the high prevalence of arterial hypertension [8], with a higher risk for cognitive impairment, either of Alzheimer or vascular type, associated with vascular risk factors [9-13]. Additionally, there are about 838,000 illiterate adults living in Portugal ( $9 \%$ of the population, mostly among the elderly and rural populations) based on the 2001 Census, with illiteracy-dependent limitation of the cognitive reserve being a proven risk factor for the earlier onset of dementia [14]. Portugal is hence supposed to have social, cultural and economical idiosyncrasies which could hypothetically justify a high prevalence of cognitive impairment and dementia, although no population study has ever been taken to prove so. Also, significant geographic disparities are acknowledged to occur in Portugal, with a meaningful part of the population residing in rural, culturally and economically disfavoured areas. Recognition of the effects of such contrasts in the risk of cognitive impairment may justify different interventions and allocation of resources in rural and urban areas.

In this context, a population-based longitudinal study (POLSCI) was set up in Northern Portugal to estimate the prevalence and incidence of dementia and CIND in rural and urban populations aged 55-79 years. The population is younger than usually targeted in most prevalence studies since one of the obiectives of the follow-up study is to elucidate about early factors affecting detection/recognition of dementia in order to develop health prevention programs to minimize and delay the impact of the disease, as it has been remarked in other studies[15]. This article presents the results of the prevalence survey undertaken in 2003.

\section{Methods}

The study was planned to involve representative rural and urban populations aged 55-79 years residing in Northern Portugal. The territorial unit "Entre Douro e Vouga" was chosen and within the area the two municipalities representing in the 2001 Census socio-demographic extremes in terms of population density (73 vs. 2.7161 inhabitants $/ \mathrm{km}^{2}$ ), number of administrative divisions ( 20 vs. 1$)$, main occupations ( $6.1 \%$ vs. $0.2 \%$ in farming and $50.5 \%$ vs. $69.6 \%$ in tertiary activities) and illiteracy $(11.7 \%$ vs. $4.8 \%)$ - Arouca (rural) with 4,941 inhabitants and Sao João da Madeira (urban) with 4,117 inhabitants within the age range (Figure 1).

The minimum sample size was estimated for a confidence level of $95 \%$, a level of precision of $2.5 \%$ and a "predicted" cognitive impairment prevalence of $16 \%$ in the rural community, since it was expected a higher prevalence than the reported in the Canadian Study of Health and Aging[3] in the 65-74 age-group (13.4\%), similar to that reported for CIND for those 65 years and older. Reporting to data from the recent 2001 Census and keeping the urban-rural balance within the country $(38.4 \%$ residing in cities and $61.6 \%$ outside), the required minimum sample size in the rural community was $\mathrm{n}=710$ $(15 \%)$ and approximately $\mathrm{n}=450(11 \%)$ in the urban community (allowing for an identical precision of $2.5 \%$ if the estimated prevalence is 9\%). Since the National Health Service has universal coverage, the two samples were drawn at random by computer from the population registered at the two community health centres by the end of 2002. Moreover, based on a preliminary study a relatively low response rate (50-60\%) was to be expected [16] and so reserve samples were created from which replacements were selected in case of non-response. The study

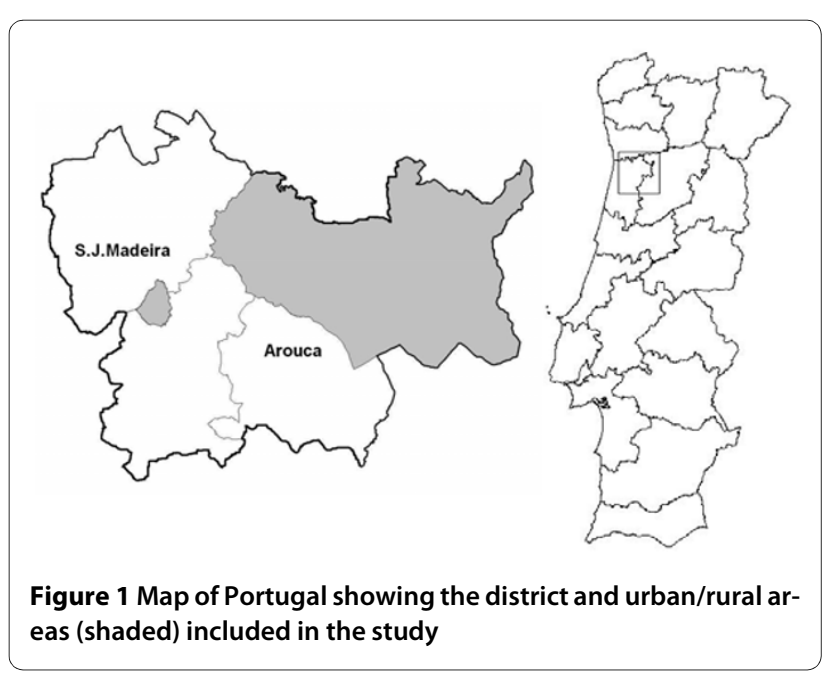


was planned to be completed in two consecutive threemonth periods, starting in July 2003 in Arouca and ending by December 2003 in Sao João da Madeira. All persons examined as part of the study were informed of the scope of the project and gave an informed consent. All study procedures and ethical aspects were approved by the Hospital S. Sebastiano ethical committee and the Health Centre directors.

\section{First Phase - Screening interview}

Sampled subjects were sent written letters describing the survey objective and welcoming their participation. They were further contacted by phone to announce the screening interview at the community health centre and were asked to come with a close friend or family member. The interview lasted 45-60 minutes and was conducted by the same team of trained psychologists in the rural and urban areas. Besides socio-demographic information, questions about the current health status and medication were included, namely information about vascular risk factors and neurological/psychiatric diseases. The short version of the Geriatric depression scale [17] and the CAGE questionnaire [18] were used to screen depression and alcoholic habits. As part of the protocol designed, Subjective memory complaints (SMC) [19] were listed and the Blessed Dementia Scale (BDS)[20] and the Mini-Mental State Examination (MMSE)[21] were applied. The Blessed Dementia Scale (BDS, Blessed G, 1968) based on a close informant assesses functional difficulties in several daily activities, change in habits (eating, dressing and sphincter control) and mood (personality, behaviour, interests and emotions) with scores within a 0-28 scale. The cut-off of 4 has high validity (sensitivity $=95 \%$ and specificity $=84 \%)$ and the overall score correlates with the patient's neuropsychological performance [22].The neuropsychological evaluation comprised a set of tests from the "Lisbon Battery" formally translated, adapted and validated for the Portuguese population: the digit span for attention and working memory, logical memory I and II (spontaneous and delayed), paired-associate learning, visual memory, verbal memory with interference, categorical verbal fluency (food products) and naming [23].

\section{Second Phase - Neurological consultation}

Screening criteria for dementia were set for an abnormal MMSE score or a BDS score of 4 points or higher. Cut-off points for the MMSE were 15 for illiterate persons, 22 for 1-11 years of education and 27 for 12 years or more, based on the validated Portuguese adaptation [24]. To establish screening criteria for CIND, MMSE scores were analysed in the rural and urban samples separately according to age and educational level, after excluding participants screening positive for dementia. This analy- sis was conducted in a sample of 1049 participants, (643 rural and 406 urban) and since age was not a significant source of variation after controlling for education, the cut-off points were set at 1 standard deviation bellow the sample's mean according to education level - 18 for illiterate, 24 for $1-3$ years, 26 for 4 years and 27 for 12 or more years - and were identical for rural and urban samples.

All participants with suspected cognitive impairment (dementia or CIND) after the initial screen or whose information was not enough for applying the previous criteria were called to attend the second phase clinical examination at the Hospital S. Sebastião, including CT scanning and laboratory analysis whenever necessary. The health centre and hospital records were reviewed to check inconsistency on current health status/medication. The definite diagnosis for those screening positive in the first phase was established by consensus between the neurologists and the psychological coordinator.

\section{Criteria for CIND, dementia and subtypes}

Dementia was diagnosed according to the DSM-IV-TR [1]. Following the definitions used in the Canadian Study oh Health and Aging [2,3], diagnoses of CIND were based on exclusion of dementia and the presence of various categories of impairment identified either in the clinical examination or in the neuropsychological tests. The categories considered were: general vascular, depression, cerebrovascular, alcohol or drug abuse, traumatic brain injury, sociocultural, psychiatric conditions, mental retardation and other neurological conditions. Whenever no medical, neurological/psychiatric condition was found for explaining cognitive impairment, it was considered cognitive impairment with no other condition (NOC).

\section{Data analysis}

In order to analyse possible non-participation bias, the distribution by gender and age of participants and nonparticipants in both communities was compared using the chi-square test. The prevalence estimates of cognitive impairment according to diagnosis, socio-demographic characteristics and comorbidity, namely number of vascular risk factors, depression, cerebrovascular disease and other disease in urban and rural populations are presented and the corresponding 95\% confidence limits (CI) were calculated by the Wilson "score" method [25]. The rural/urban prevalence ratios (PR) of cognitive impairment were used to compare the prevalence in both settings. Since sample weights represent the rural/urban balance in the overall Portuguese population, the overall prevalence estimates of dementia and CIND were calculated from the respondents' sample. Logistic regression models were used to adjust for the presence of multiple factors to ascertain the independent factors associated with dementia and CIND. Besides the main effects mod- 
els, the importance of rural/urban environment was tested by including all interaction terms involving residence and the remaining variables in the model using a stepwise procedure. A probability value of 0.05 was used as the limit for Type I error (wrongly rejecting the null hypothesis).

\section{Results}

After a six-month period, 1315 persons $(26.8 \%$ of the population) were contacted in the rural area (from July to December 2003), and 863 persons (21.0\%) were contacted in the urban area (from March to May 2004) (Figure 2). The response rate was higher in the rural sample $(59.2 \%$ vs. $51.8 \%$; chi-square $=11.5, \mathrm{df}=1, \mathrm{p}<0.001$ ), but since information was incomplete for $3.6 \%$ of rural respondents, the overall participation rate $(52.6 \%)$ was not significantly different in the two communities (chi-square = $3.4, \mathrm{df}=1, \mathrm{p}<0.06)$. Though in the urban community women were more willing to participate than men (chisquare $=9.2, \mathrm{df}=1, \mathrm{p}<0.003)$, the distribution by age of male and female participants and non-participants was not significantly different both in the rural and urban communities (chi-square $<6.4, \mathrm{df}=4, \mathrm{p}<0.1$ ) (Figure 3 ).

Based on the screening criteria for dementia, 97 persons were selected for the second phase neurological consultation (Figure 2). Among these, 31 were ultimately diagnosed with dementia and 55 with CIND. After applying criteria for CIND to the remaining 1049 participants, 167 screened positive and were selected for the second phase consultation - 86 of which were ultimately diagnosed as CIND. Overall, 172 persons were diagnosed as cognitively impaired, $16.8 \%$ in the rural community and $12.0 \%$ in the urban one, rural/urban PR $=1.40(95 \% \mathrm{CI}$ : 1.04-1.90) (Table 1). In general there is a higher prevalence of cognitive impairment in rural compared to urban populations for all population strata considered, reaching the highest prevalence ratios in the oldest (2.16), illiterate (2.05) and dependent (2.21). The prevalence ratios are not so high in the presence of comorbidity, ranging from 1.0 to 1.3 ; the only exception is in persons with two or more VRF, for which the prevalence is $24.8 \%$ in the rural area compared to $11.3 \%$ in the urban area. In these strata the prevalence in the rural community is remarkably

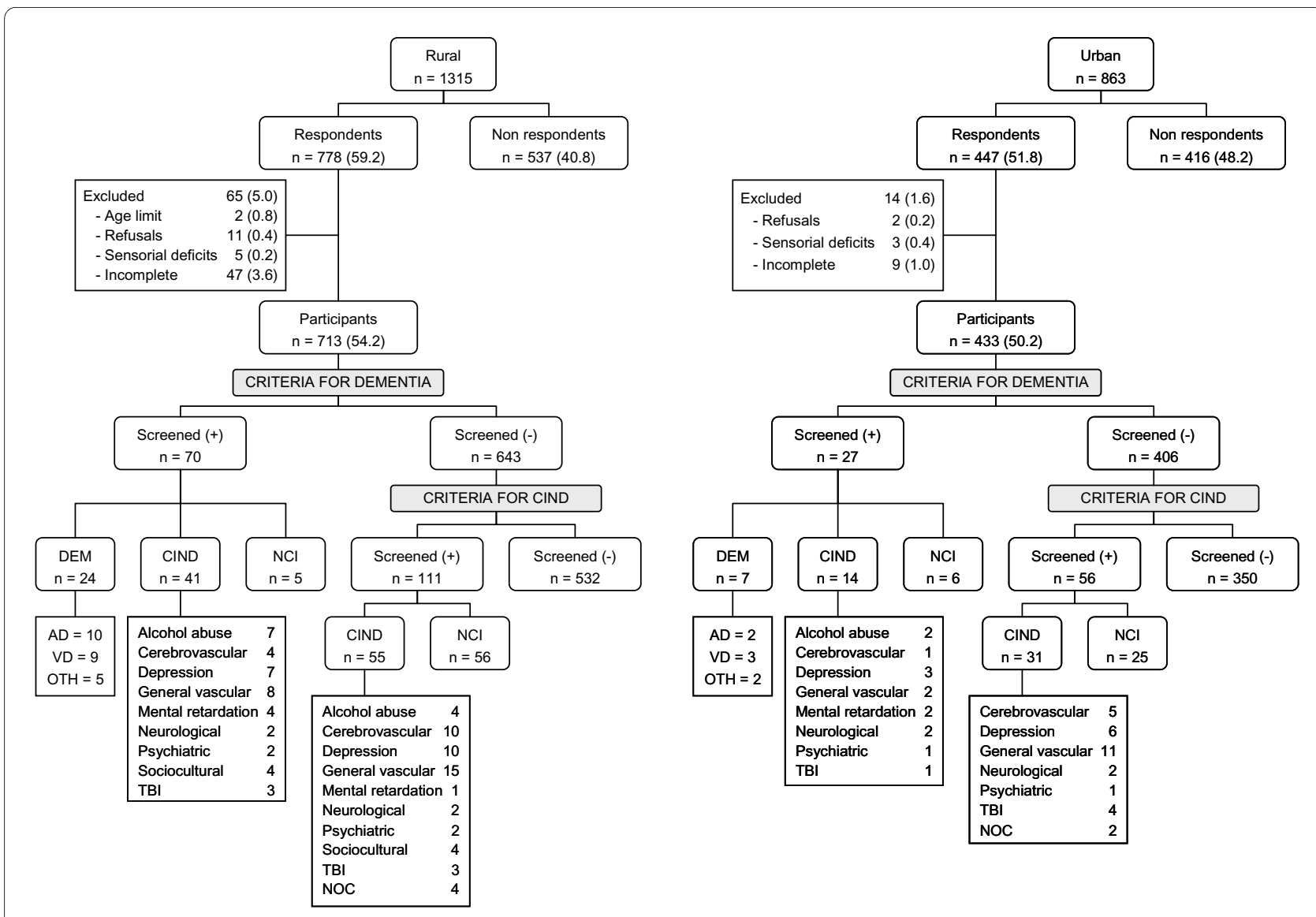

Figure 2 Sample, participants and cognitive impairment classification. General vascular: with at least one vascular risk factor (high blood pressure, cardiac disease, diabetes and dyslipidemia); TBI: traumatic brain injury; NOC: no other condition 


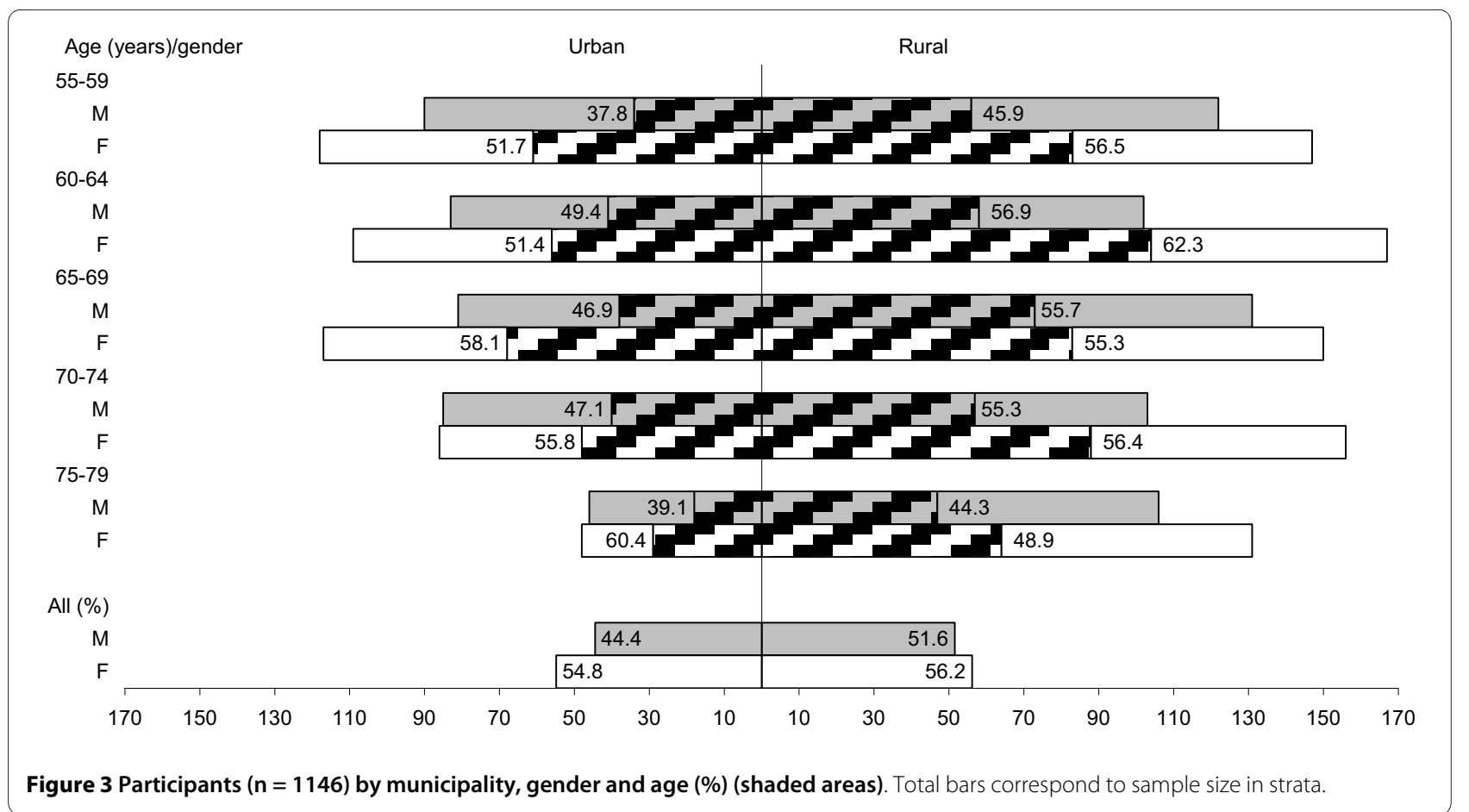

high, almost one third of the population aged 75-79 years and just over one forth of illiterates or persons living alone compared with at most $15 \%$ of the urban population in the same strata. Another rural stratum particularly vulnerable are persons depending on others, near one half are cognitively impaired compared to $22.2 \%$ in the urban population. On the other hand the urban population not illiterate but with low levels of education seem more affected than the illiterates and the reverse trend happens in the rural population.

\section{Prevalence and pattern of dementia and CIND}

The overall prevalence of dementia was $2.7 \%$ (95\% CI: 1.9-3.8), increasing steeply with age and decreasing with education level (Table 2). The prevalence of CIND was 12.3\% (95\% CI: 10.4-14.4) following dementia patterns in terms of age and education, but unlike dementia, tending to be higher in women compared to men, $14.2 \%$ vs. $9.5 \%$. The prevalence of both CIND and dementia were higher in the rural area, in farmers, retired or dependent persons. Considering simultaneously the main effects of socio-demographic characteristics and comorbidity in a logistic regression model, the prevalence of dementia is associated with age, cerebrovascular disease and other neurological disease. The odds of dementia increases by $11 \%$ (95\% CI: 3-18\%) for an aging of one year and in persons with cerebrovascular disease $(\mathrm{OR}=9.2,95 \% \mathrm{CI}$ : 4.120.5) or other diseases (OR $=3.6,95 \%$ CI: 1.6-8.0) (Table 3). CIND was associated with the same factors but also with education, VFR and depression. Including in the model for CIND all interactions of factors with residen- tial area in a stepwise procedure, there was a significant interaction of residence and age, that is, the rural/urban odds ratio of CIND increases by 1.07 (95\% CI: 1.0-1.13) every year, corroborating the values shown in Table 1 . Less educated persons (OR $=1.54,95 \%$ CI: 1.02-2.33) and, as for dementia, persons with comorbid conditions are also at a higher risk of having CIND.

Among the 31 cases of dementia identified, equal proportions of $\mathrm{AD}$ and $\mathrm{VaD}$ were diagnosed, a prevalence of 10.5 per 1000 population, followed by dementia induced by alcohol abuse, 1.7 per 1000 population, and in three cases clinical information did not warrant a definite diagnosis (Table 4). Both $\mathrm{AD}$ and $\mathrm{VaD}$ were more prevalent in rural settings ( $R: U=3.0$ and 1.8 , respectively), but while $\mathrm{AD}$ was more prevalent among women $(\mathrm{F}: \mathrm{M}=2.0)$ and patients had a median age of 75 years, VaD was more prevalent in men $(\mathrm{F}: \mathrm{M}=0.3)$ and patients had a median age of 70.4 years.

The more frequent categories of CIND were cumulative vascular risk factors (eg, hypertension, cardiac disease, diabetes and/or dyslipidemia) (31.4\%), followed by depression (18.4\%) and cerebrovascular disease (more commonly previous stroke) (14.2\%). Socio-cultural isolation (5.7\%) and other neurological/psychiatric diseases were less frequent. CIND categories had different patterns in terms of gender (chi-square $=38.2, \mathrm{df}=9, \mathrm{p}<$ 0.007), education level (chi-square $=22.8, \mathrm{df}=9, \mathrm{p}<$ 0.007 ) and MMSE score (chi-square $>37.1, \mathrm{df}=9, \mathrm{p}<$ 0.001). While depression was more prevalent in women ( $\mathrm{F}: \mathrm{M}=8.1$ ) and sociocultural isolation or mental retarda- 
Table 1: Prevalence of cognitive impairment in rural and urban populations by socio-demographic characteristics and comorbidity

\begin{tabular}{|c|c|c|c|c|c|c|c|c|c|c|}
\hline \multirow[t]{2}{*}{ Characteristics } & \multicolumn{4}{|c|}{ Rural } & \multicolumn{4}{|c|}{ Urban } & \multirow[t]{2}{*}{$\mathbf{P R}$} & \multirow[t]{2}{*}{$95 \% \mathrm{Cl}$} \\
\hline & $\mathbf{N}$ & No cases & Prev (\%) & $95 \% \mathrm{Cl}$ & $\mathbf{N}$ & No cases & Prev (\%) & $\mathrm{Cl} 95 \%$ & & \\
\hline All & 713 & 120 & 16.8 & $14.3-19.8$ & 433 & 52 & 12.0 & $9.3-15.4$ & 1.40 & $1.04-1.90$ \\
\hline \multicolumn{11}{|l|}{ Gender } \\
\hline Men & 291 & 43 & 14.8 & $11.2-19.3$ & 171 & 16 & 9.4 & $5.8-14.7$ & 1.58 & $0.92-2.72$ \\
\hline Women & 422 & 77 & 18.2 & $14.9-22.2$ & 262 & 36 & 13.7 & $10.1-18.4$ & 1.33 & $0.92-1.91$ \\
\hline \multicolumn{11}{|l|}{ Age (years) } \\
\hline $55-64$ & 294 & 30 & 10.2 & $7.2-14.2$ & 192 & 18 & 9.4 & $6.0-14.3$ & 1.09 & $0.63-1.90$ \\
\hline $65-74$ & 301 & 52 & 17.3 & $13.4-22.0$ & 194 & 27 & 13.9 & $9.8-19.5$ & 1.24 & $0.81-1.91$ \\
\hline $75-79$ & 118 & 38 & 32.2 & $24.5-41.1$ & 47 & 7 & 14.9 & $7.4-27.7$ & 2.16 & $1.04-4.50$ \\
\hline \multicolumn{11}{|l|}{ Education } \\
\hline Illiterate & 189 & 50 & 26.5 & $20.7-33.2$ & 31 & 4 & 12.9 & $5.1-28.9$ & 2.05 & $0.80-5.28$ \\
\hline $1-3$ & 226 & 39 & 17.3 & $12.9-22.7$ & 103 & 21 & 20.4 & $13.7-29.2$ & 0.85 & $0.53-1.36$ \\
\hline 4 & 273 & 28 & 10.3 & 7.2-14.4 & 206 & 20 & 9.7 & $6.4-14.5$ & 1.06 & $0.61-1.82$ \\
\hline 5 or more & 21 & 3 & 12.0 & $4.2-30.0$ & 75 & 7 & 7.5 & $3.7-14.7$ & 1.59 & $0.44-5.73$ \\
\hline \multicolumn{11}{|l|}{ Residential status } \\
\hline Living with the family & 652 & 104 & 16.0 & $13.3-19.0$ & 388 & 45 & 11.6 & $8.8-15.2$ & 1.38 & $0.99-1.91$ \\
\hline Living alone & 57 & 15 & 26.3 & $16.7-38.9$ & 42 & 6 & 14.3 & $6.7-27.8$ & 1.84 & $0.78-4.35$ \\
\hline $\begin{array}{l}\text { Institutional } \\
\text { residence }\end{array}$ & 4 & 1 & 25.0 & $4.5-69.9$ & 3 & 1 & 33.3 & $6.2-79.2$ & 0.75 & $0.07-7.73$ \\
\hline \multicolumn{11}{|l|}{ Occupation (present/late) } \\
\hline Farming & 402 & 76 & 18.9 & $15.4-23.0$ & 19 & 6 & 31.6 & $15.4-54.0$ & 0.60 & $0.30-1.20$ \\
\hline Production & 86 & 12 & 14.0 & $8.2-22.8$ & 153 & 20 & 13.1 & $8.6-19.3$ & 1.07 & $0.55-2.08$ \\
\hline Personal care/serving & 72 & 13 & 18.1 & $10.9-28.5$ & 117 & 14 & 12.0 & 7.3-19.1 & 1.51 & $0.75-3.03$ \\
\hline Sales/White collar & 50 & 4 & 8.0 & $3.2-18.8$ & 112 & 7 & 6.3 & $3.1-12.3$ & 1.28 & $0.39-4.18$ \\
\hline Housewife & 103 & 15 & 14.6 & $9.0-22.6$ & 32 & 5 & 15.6 & $6.9-31.8$ & 0.93 & $0.37-2.37$ \\
\hline \multicolumn{11}{|l|}{ Retired worker } \\
\hline Yes & 499 & 100 & 20.0 & $16.8-23.8$ & 282 & 37 & 13.1 & $9.7-17.6$ & 1.53 & $1.08-2.16$ \\
\hline No & 214 & 20 & 9.3 & $6.1-14.0$ & 151 & 15 & 9.9 & $6.1-15.7$ & 0.94 & $0.50-1.78$ \\
\hline \multicolumn{11}{|l|}{ Depending on others } \\
\hline Yes & 53 & 26 & 49.1 & $36.1-62.1$ & 18 & 4 & 22.2 & $9.0-45.2$ & 2.21 & $0.89-5.47$ \\
\hline No & 660 & 94 & 14.2 & $11.8-17.1$ & 415 & 48 & 11.6 & $8.8-15.0$ & 1.23 & $0.89-1.71$ \\
\hline \multicolumn{11}{|l|}{ Physical/Mental comorbidity } \\
\hline \multicolumn{11}{|l|}{ Depression } \\
\hline Yes & 78 & 25 & 32.1 & $22.8-43.0$ & 50 & 13 & 25.0 & $15.2-38.2$ & 1.28 & $0.72-2.27$ \\
\hline No & 635 & 95 & 15.0 & $12.4-17.9$ & 381 & 39 & 10.2 & 7.6-13.7 & 1.46 & $1.03-2.08$ \\
\hline \multicolumn{11}{|l|}{ Cerebrovascular disease } \\
\hline Yes & 63 & 27 & 42.9 & $31.4-55.1$ & 26 & 10 & 38.5 & $22.4-57.5$ & 1.11 & $0.63-1.96$ \\
\hline No & 650 & 93 & 14.3 & $11.8-17.2$ & 407 & 42 & 10.3 & 7.7-13.7 & 1.39 & $0.98-1.95$ \\
\hline \multicolumn{11}{|l|}{ Other disease ${ }^{\dagger}$} \\
\hline Yes & 124 & 47 & 37.9 & $29.8-46.7$ & 59 & 21 & 35.6 & $24.6-48.3$ & 1.07 & $0.71-1.61$ \\
\hline No & 589 & 73 & 12.4 & $10.0-15.3$ & 374 & 31 & 8.3 & $5.9-11.5$ & 1.50 & $1.00-2.23$ \\
\hline \multicolumn{11}{|l|}{ No vascular risk factors ${ }^{\ddagger}$} \\
\hline 0 & 383 & 50 & 13.1 & $10.0-16.8$ & 237 & 19 & 8.0 & $5.2-12.2$ & 1.63 & $0.99-2.69$ \\
\hline 1 & 229 & 45 & 19.7 & $15.0-25.3$ & 134 & 26 & 19.4 & $13.6-26.9$ & 1.01 & $0.66-1.56$ \\
\hline 2 or more & 101 & 25 & 24.8 & $17.4-34.0$ & 62 & 7 & 11.3 & $5.6-21.5$ & 2.19 & $1.01-4.76$ \\
\hline
\end{tabular}

Prev: prevalence; PR: Rural/Urban prevalence ratio; ${ }^{\dagger}$ at least one of: traumatic brain injury, alcohol abuse, psychiatric or other neurological disease; ¥Vascular risk factors include high blood pressure, cardiac disease, diabetes and dyslipidemia 
Table 2: Prevalence of CIND and dementia by socio-demographic characteristics and comorbidity

\begin{tabular}{|c|c|c|c|c|c|c|c|}
\hline \multirow[b]{2}{*}{ Characteristics } & \multicolumn{4}{|c|}{ CIND } & \multicolumn{3}{|c|}{ Dementia } \\
\hline & $\mathbf{N}$ & No cases & Prev (\%) & $95 \% \mathrm{Cl}$ & No cases & Prev (\%) & $95 \% \mathrm{Cl}$ \\
\hline All & 1146 & 141 & 12.3 & $10.4-14.4$ & 31 & 2.7 & $1.9-3.8$ \\
\hline \multicolumn{8}{|l|}{ Residence } \\
\hline Rural & 713 & 96 & 13.5 & $11.1-16.2$ & 24 & 3.4 & $2.3-5.0$ \\
\hline Urban & 433 & 45 & 10.4 & 7.9-13.6 & 7 & 1.6 & $0.8-3.3$ \\
\hline \multicolumn{8}{|l|}{ Age (years) } \\
\hline $55-59$ & 228 & 22 & 9.6 & $6.5-14.2$ & 1 & 0.4 & $0.1-2.4$ \\
\hline $60-64$ & 258 & 21 & 8.1 & $5.4-12.1$ & 4 & 1.6 & $0.6-3.9$ \\
\hline $65-69$ & 258 & 28 & 10.9 & $7.6-15.2$ & 4 & 1.6 & $0.6-3.9$ \\
\hline $70-74$ & 237 & 37 & 15.6 & $11.5-20.8$ & 10 & 4.2 & $2.3-7.6$ \\
\hline $75-79$ & 165 & 33 & 20.0 & $14.6-26.8$ & 12 & 7.3 & $4.2-12.3$ \\
\hline \multicolumn{8}{|l|}{ Gender } \\
\hline Men & 462 & 44 & 9.5 & $7.2-12.5$ & 15 & 3.2 & $2.0-5.3$ \\
\hline Women & 684 & 97 & 14.2 & $11.8-17.0$ & 16 & 2.3 & $1.5-3.8$ \\
\hline \multicolumn{8}{|l|}{ Education (years) } \\
\hline Illiterate & 220 & 45 & 20.5 & $15.6-26.3$ & 9 & 4.1 & $2.2-7.6$ \\
\hline $1-3$ & 329 & 47 & 14.3 & $10.9-18.5$ & 13 & 4.0 & $2.3-6.6$ \\
\hline 4 & 479 & 41 & 8.5 & $6.3-11.4$ & 7 & 1.5 & $0.7-3.0$ \\
\hline 5 or more & 118 & 8 & 6.8 & $3.5-12.8$ & 2 & 1.7 & $0.5-6.0$ \\
\hline \multicolumn{8}{|l|}{ Residential status } \\
\hline Living alone & 99 & 20 & 20.2 & $13.5-29.2$ & 1 & 1.0 & $0.2-5.5$ \\
\hline Living with the family & 1040 & 119 & 11.4 & $9.7-13.5$ & 30 & 2.9 & $2.0-4.1$ \\
\hline Institutional residence & 7 & 2 & 28.6 & $8.2-64.1$ & 0 & 0.0 & $0.0-35.4$ \\
\hline \multicolumn{8}{|l|}{ Occupation (present/late) } \\
\hline Farming & 421 & 64 & 15.2 & $12.1-18.9$ & 18 & 4.3 & $2.7-6.7$ \\
\hline Production & 239 & 27 & 11.3 & $7.9-15.9$ & 5 & 2.1 & $0.9-4.8$ \\
\hline Personal care \& serving & 189 & 24 & 12.7 & $8.7-18.2$ & 3 & 1.6 & $0.5-4.6$ \\
\hline Sales/White collar & 162 & 9 & 5.6 & $3.0-10.2$ & 2 & 1.2 & $0.3-4.4$ \\
\hline Housewife (not rewarded) & 135 & 17 & 12.6 & $8.0-19.2$ & 3 & 2.2 & $0.8-6.3$ \\
\hline \multicolumn{8}{|l|}{ Retired worker } \\
\hline Yes & 781 & 110 & 14.1 & $11.8-16.7$ & 27 & 3.5 & $2.4-5.0$ \\
\hline No & 365 & 31 & 8.5 & $6.1-11.8$ & 4 & 1.1 & $0.4-2.8$ \\
\hline \multicolumn{8}{|l|}{ Depending on others } \\
\hline Yes & 71 & 20 & 28.2 & 19.0-39.5 & 10 & 14.1 & $7.8-24.0$ \\
\hline No & 1075 & 121 & 11.3 & $9.5-13.3$ & 21 & 2.0 & $1.3-3.0$ \\
\hline \multicolumn{8}{|l|}{ Physical/Mental comorbidity } \\
\hline \multicolumn{8}{|l|}{ Depression } \\
\hline Yes & 130 & 34 & 26.2 & $19.4-34.3$ & 4 & 3.1 & $1.2-7.7$ \\
\hline No & 1016 & 107 & 10.5 & $8.8-12.6$ & 27 & 2.7 & $1.8-3.8$ \\
\hline \multicolumn{8}{|l|}{ Cerebrovascular disease } \\
\hline Yes & 89 & 22 & 24.7 & $16.9-34.6$ & 15 & 16.9 & $10.5-26.0$ \\
\hline No & 1057 & 119 & 11.3 & $9.5-13.3$ & 16 & 1.5 & $0.9-2.4$ \\
\hline
\end{tabular}


Table 2: Prevalence of CIND and dementia by socio-demographic characteristics and comorbidity (Continued)

\begin{tabular}{|c|c|c|c|c|c|c|c|}
\hline \multicolumn{8}{|l|}{ Other disease $^{\dagger}$} \\
\hline Yes & 183 & 55 & 30.1 & $23.9-37.1$ & 13 & 7.1 & $4.2-11.8$ \\
\hline No & 963 & 86 & 8.9 & $7.3-10.9$ & 18 & 1.9 & $1.2-2.9$ \\
\hline \multicolumn{8}{|c|}{ No vascular risk factors ${ }^{\ddagger}$} \\
\hline 0 & 620 & 57 & 9.2 & $7.2-11.7$ & 12 & 1.9 & $1.1-3.4$ \\
\hline 1 & 363 & 57 & 15.7 & $12.3-19.8$ & 14 & 3.9 & $2.3-6.4$ \\
\hline 2 or more & 163 & 27 & 16.6 & $11.6-23.0$ & 5 & 3.1 & $1.3-7.0$ \\
\hline
\end{tabular}

Prev: prevalence; ${ }^{\dagger}$ at least one of: traumatic brain injury, alcohol abuse, psychiatric or other neurological disease; $\neq \vee$ ascular risk factors include

high blood pressure, cardiac disease, diabetes and dyslipidemia

tion were only observed in women, traumatic brain injury or alcohol abuse were more prevalent in men ( $\mathrm{F}: \mathrm{M}=0.1$ and 0.4 , respectively), the later more prevalent in rural areas ( $\mathrm{R}: \mathrm{U}=3.3)$. Education level and MMSE performance tend to correlate among CIND persons, outlining two relatively homogeneous groups: low MMSE scores and low education level in the socio-cultural, mental retardation and alcohol abuse categories, and relatively high MMSE scores and education level in persons with psychiatric/neurological diseases. The remaining categories attained medium values for both variables.

\section{Discussion}

The adoption of preventive strategies and rational allocation of resources to lessen the impact of dementia in the community population depend mostly on knowing the prevalence of cognitive impairment and the relative importance of its determinants. Given the lack of epidemiological data in our country, the POLSCI study was set up to estimate the prevalence and incidence of cognitive impairment in rural and urban populations from Northern Portugal, with the present paper reporting on the results from the first stage prevalence survey undertaken in 2003. As expected the prevalence of cognitive impairment was higher in rural compared to urban populations, the prevalence more than doubling in those aged 75-79 years and in those with two or more vascular risk factors. This pattern is replicated in CIND and dementia. Age, education level, vascular risk factors and co-morbid conditions (cerebrovascular disease, depression and other neurological/psychiatric disease) were determining factors of CIND both in rural or urban populations. Nevertheless the contrast between rural and urban environments is evidenced throughout the age span, the estimated rural/urban relative risk of CIND increasing with age, that is, a similar risk in the urban compared with the rural youngest populations and a higher risk in the rural compared with the urban oldest populations. Independent predictors of dementia were age and associated co-morbidity, especially the 9 times higher risk of dementia among those with cerebrovascular disease.
These results point out the relatively high importance of both vascular risk factors and cerebrovascular disease in the patterns of cognitive impairment in the studied population. Indeed $\mathrm{AD}$ and $\mathrm{VaD}$ are equally likely in this age band (55-79 years) and nearly 40\% of all CIND persons have cumulative vascular risk factors or a past history of cerebrovascular disease, pointing not only to the fact that a vascular pathogenesis underlies most cognitive impairment, but also that vascular cognitive impairment is probably a continuum which can in many patients be manifested only as cognitive impairment no dementia. Indeed $\mathrm{VaD}$ and $\mathrm{AD}$ have been theorized to have a transition period between normal cognition and dementia, with preclinical impairment compromising performance in several cognitive tests without a formal functional handicap [26]. With stroke being the more frequent cause of death in Portugal, one has to admit that "vascular CIND" (vCIND) could also be relatively more prevalent in Portugal thus reinforcing the importance of a proactive prevention of modifiable vascular risk factors.

In accordance with previous studies the overall prevalence of both CIND and dementia increased with age and decreased in persons with higher levels of education [4,27-31]. The prevalence of dementia in the youngest is similar to that found in the Netherlands [32] and higher than in the USA[33] or UK[34] but among the eldest (7579 years) is higher than the reported in most European countries $[4,32,35-40]$. The slightly higher prevalence of dementia in men (3.2 vs. $2.3 \%$ ) may be linked to the AD and $\mathrm{VaD}$ balance, the former more common among men and the later among women [41]. This balance is rather unusual in other European countries (eg. AD:VaD ratios of 3 in Great Britain or 2 in Italy) and approaches the vascular-preponderant reports from Japan and China $(\mathrm{AD}: \mathrm{VaD}=0.6)[42]$. Actually, ratios resembling the European trend wouldn't be possible even if one were to consider the $10 \%$ of demented patients with undetermined diagnosis as 'probable-AD'. In Japan, the higher prevalence of $\mathrm{VaD}$ has been attributed to the high salt intake, traditional Japanese diet, and high stroke mortality [43]. Similar features can be found in the Portuguese popula- 
Table 3: Socio-demographic characteristics and comorbidity associated with CIND and dementia

\begin{tabular}{|c|c|c|c|c|c|c|}
\hline \multirow[t]{3}{*}{ Characteristics } & \multicolumn{4}{|c|}{ CIND } & \multirow{2}{*}{\multicolumn{2}{|c|}{$\begin{array}{c}\text { Dementia } \\
\text { Main effects model }\end{array}$}} \\
\hline & \multicolumn{2}{|c|}{ Main effects model } & \multicolumn{2}{|c|}{ Interaction model } & & \\
\hline & OR & $95 \% \mathrm{Cl}$ & OR & $95 \% \mathrm{Cl}$ & OR & $95 \% \mathrm{Cl}$ \\
\hline Age (years) & $1.06^{+}$ & $1.03-1.09$ & 1.01 & $0.96-1.07$ & $1.11^{\dagger}$ & $1.03-1.18$ \\
\hline \multicolumn{7}{|l|}{ Residence } \\
\hline Rural vs. Urban & 1.20 & $0.80-1.79$ & $0.02^{*}$ & $0.01-0.96$ & 1.44 & $0.57-3.66$ \\
\hline \multicolumn{7}{|l|}{ Gender } \\
\hline Women vs. Men & 1.42 & $0.94-2.13$ & 1.41 & $0.94-2.13$ & 0.80 & $0.35-1.81$ \\
\hline \multicolumn{7}{|l|}{ Education (years) } \\
\hline $0-3$ vs. 4 or more & $1.54^{*}$ & $1.02-2.33$ & $1.54^{*}$ & $1.02-2.33$ & 1.42 & $0.56-3.59$ \\
\hline \multicolumn{7}{|l|}{ VRF } \\
\hline Yes vs. No & $1.53^{*}$ & $1.05-2.22$ & $1.53^{*}$ & $1.05-2.22$ & 1.11 & $0.49-2.49$ \\
\hline \multicolumn{7}{|l|}{ CVD } \\
\hline Yes vs. No & $4.15^{\ddagger}$ & $2.48-6.96$ & $4.13^{\ddagger}$ & $2.46-6.93$ & $9.23^{\ddagger}$ & $4.16-20.5$ \\
\hline \multicolumn{7}{|l|}{ Depression } \\
\hline Yes vs. No & $3.13^{\ddagger}$ & $1.95-5.03$ & $3.16^{\ddagger}$ & $1.96-5.08$ & 1.30 & $0.40-4.23$ \\
\hline \multicolumn{7}{|l|}{ Other disease } \\
\hline Yes vs. No & $5.95^{\ddagger}$ & $3.96-8.94$ & $6.05^{\ddagger}$ & $4.02-9.10$ & $3.59^{\dagger}$ & $1.61-8.00$ \\
\hline Residence ${ }^{*}$ Age & & & $1.07^{*}$ & $1.00-1.13$ & & \\
\hline
\end{tabular}

tion, with a known higher salt intake and higher stroke incidences, as compared to other western European countries [6-8]. A high prevalence of vascular risk factors may be the underlying reason for this 'VaD boost', as $31.7 \%$ of the study's participants had one risk factor, and $14.2 \%$ had at least two. Vascular risk factors are, in fact, known to be highly prevalent in the Portuguese population, with more than half of the Portuguese aged 65-84 years having hypertension, $17.8 \%$ having diabetes, and more than $5 \%$ already having had a stroke or myocardial infarction[8]. As in other studies, either in Caucasian or Oriental populations $[43,44]$, patients with $\mathrm{VaD}$ were younger than those with $\mathrm{AD}$ (median age: 70.4 vs 75.0 years).

Unlike dementia, CIND was more prevalent in women (14.2 vs. $9.5 \%)$ as in other studies [30,31]. Illiteracy was more frequent in women than men (23.1 vs $13.4 \%)$ and may be partially responsible for the female preponderance in CIND, since association with socio-cultural factors and mental retardation were specific of women. Anyway vascular risk factors were actually the most common aetiological association for CIND in both men and women, illustrating their widespread effects. Other "organic" causes of CIND (as alcoholism and TBI) were more common among men, and CIND with no associated "organic" co-morbidity (depression, sociocultural isolation) was more frequent among women. The latter follows the AD pattern, leading to the hypothesis of a more purely degenerative pathogenesis of the CINDdementia continuum in many women. Interestingly, other authors have pointed out that the true importance of vCIND cases has often been underappreciated, since it has been demonstrated that it can associate with rates of institutionalization and mortality similar to the ones found in AD [45]. In fact, vCIND must be faced as the most prevalent form of vascular cognitive impairment, also comprising $\mathrm{VaD}$ and mixed $\mathrm{AD}-\mathrm{VaD}$.

Another interesting finding was that the prevalence of dementia more than doubled in population strata without formal education (4.1 vs 1.7\%) and half of demented persons had just two years of formal education. Illiteracyimposed restriction of the cognitive reserve is a proven cause for an earlier onset of dementia, with low-educated persons demonstrating less tolerance to the neuropathologic effects of dementia and presenting clinically sooner [14]. In fact, illiteracy and unskilled occupations have 
Table 4: Distribution of cognitive status and subcategories of CIND and dementia

\begin{tabular}{|c|c|c|c|c|c|c|c|}
\hline Cognitive status & $\mathbf{N}$ & $\%$ & R:U & F:M & Age (years) & Education (years) & MMSE score \\
\hline $\mathrm{NCl}$ & 974 & & 0.94 & 0.96 & $66.2(5)$ & $4.0(1)$ & $28.0(2)$ \\
\hline CIND & 141 & & 1.3 & 1.5 & $69.9(6)$ & $3.0(2)$ & $22.0(3)$ \\
\hline General vascular & 36 & 25.5 & 1.1 & 1.8 & $70.1(7)$ & $3.0(2)$ & $23.5(3)$ \\
\hline Depression & 26 & 18.4 & 1.1 & 8.1 & $69.6(4)$ & $3.0(2)$ & $23.0(2)$ \\
\hline Cerebrovascular & 20 & 14.2 & 1.4 & 1.3 & $69.7(5)$ & $3.0(2)$ & $22.5(4)$ \\
\hline Alcohol abuse & 13 & 9.2 & 3.3 & 0.1 & $69.5(5)$ & $1.0(2)$ & $19.0(3)$ \\
\hline Traumatic brain injury & 11 & 7.8 & 0.7 & 0.4 & $68.6(7)$ & $2.0(2)$ & $22.0(3)$ \\
\hline Sociocultural & 8 & 5.7 & $8 \mid 0$ & $8 \mid 0$ & $75.2(5)$ & $0.5(1)$ & $18.0(3)$ \\
\hline Other neurological & 8 & 5.7 & 0.6 & 1.1 & $73.4(3)$ & $4.0(3)$ & $26.0(4)$ \\
\hline Mental retardation & 7 & 5.0 & 1.5 & $7 \mid 0$ & $65.4(8)$ & $0.0(0)$ & $14.0(3)$ \\
\hline Psychiatric & 6 & 4.3 & 1.2 & 0.7 & $67.0(7)$ & $4.0(3)$ & $26.0(3)$ \\
\hline No other condition & 6 & 4.3 & 1.2 & 3.4 & $66.9(8)$ & $2.5(2)$ & $23.5(4)$ \\
\hline Dementia & 31 & & 2.1 & 0.7 & $73.9(4)$ & $2.0(2)$ & $17.0(4)$ \\
\hline$A D$ & 12 & 38.7 & 3.0 & 2.0 & $75.0(7)$ & $2.0(2)$ & $18.5(5)$ \\
\hline Vascular & 12 & 38.7 & 1.8 & 0.3 & $70.4(4)$ & $2.5(2)$ & $17.0(4)$ \\
\hline Alcohol & 2 & 6.5 & 0.6 & $0 \mid 2$ & $75.2(4)$ & $0.5(1)$ & $18.0(3)$ \\
\hline Parkinson & 1 & 3.2 & $1 \mid 0$ & $1 \mid 0$ & 74.1 & 3.0 & 20.0 \\
\hline Rapidly progressive & 1 & 3.2 & $1 \mid 0$ & $0 \mid 1$ & 71.5 & 11.0 & 24.0 \\
\hline Unclassifiable & 3 & 12.9 & $3 \mid 0$ & 1.4 & $76.7(2)$ & $1.0(2)$ & $12.0(6)$ \\
\hline
\end{tabular}

$\mathrm{R}: \mathrm{U}$ - rural urban prevalence ratio; F:M - female/male prevalence ratio; median and interquartile deviation for other variables; whenever category is empty the ratio is indicated by a vertical line (|); MMSE: Mini Mental State Examination

been widely described in the literature as risk factors for dementia and are known to be heavily present in our population, especially in rural areas $[28,29]$. According to the 2001 Census, $28.7 \%$ of the Portuguese population has at most 3 years of formal education, and as much as $19.2 \%$ of them are illiterate, these proportions increasing to $31.7 \%$ and $26.5 \%$, respectively, in rural populations. It has also been argued that, because of a less intellectuallydemanding context in low-income areas, functional impairment may go unnoticed for a longer time, erroneously increasing the prevalence of dementia in developed areas. Since functional impairment is taken as mandatory for the diagnosis of dementia, some believe that current dementia criteria may therefore under-estimate the impact of cognitive impairment and the actual prevalence of dementia in low and middle income countries. This may be the reason why the rural/urban environment modifies the effect of age on CIND, that is, the rural/ urban relative risk increasing with age. If this perspective were true, the present findings could conceal an even more expressive impact of rurality, low-education and low-income in the Portuguese population, especially at rural areas $[46,47]$.

The POLSCI study has nevertheless some limitations. Since the study primary goal was to assess the overall prevalence of cognitive impairment, CIND and dementia, sample size estimates were based on previous reports on the prevalence of cognitive impairment in Canadian populations aged 65-74 years[3]. Even admitting that sample sizes may appear relatively small comparing to previous studies (less than 1000 participants each), the authors acknowledge the lost of power in statistical tests and low precision of some estimates, but the limited resources allocated to the project constrained more ambitious goals. Even so to reach the required minimum sample size the study lasted for 9 months instead of the 6 months previously planned. Restriction to the 55-79 years age band also assumedly neglects all cases of cognitive impairment among the 'very old', justified not only by logistic constraints but more importantly by the predicted low response and participation rates, resulting from physical constraints and reduced collaboration on testing among the eldest. During the follow-up of these cohorts of rural and urban populations data on incidence will clarify the prevalence estimates obtained. The present results can only be assumed to represent the reality of a relatively young age-group still amenable of preventive measures, and therefore focused on cognitive impairment rather than dementia. Even so the participation rate (52.6\%) was lower than expected and lower than in previ- 
ous studies [16], which possibly results from targeting younger population strata than seen in most prevalence studies, with the youngest participants still employed and less predisposed for attending an appointment at the local health centre. In the urban community women were in general more willing to participate than men, and so if we assume that women are more prone to CIND or dementia than men, the urban overall prevalence might be overestimated. Other studies have nevertheless reported that before the age of 80 the incidence of dementia is higher in men[48], what might be a reason for an underestimation of the prevalence in the urban environment. Irrespective of the residential area it is more likely that this is the situation, since in general non-participants tend to be more cognitively impaired than participants [49]. Since age is the more important predictor of cognitive impairment and the age distribution of men and women participants and non-participants from both rural and urban areas was not significantly different and similar to the population of the 2001 Census, the overall estimates of dementia and CIND should mirror the urban/rural mix in whole Portugal.

\section{Conclusions}

To our knowledge, this is the first study to assess the prevalence of cognitive loss in the Portuguese population, and the results corroborate the expected high prevalence of cognitive impairment (CIND and dementia), as much as the assumption that Portugal may indeed be a paradigmatic example for regional variations in dementia among other countries, both in terms of rural-urban environments and socio-cultural disparities. Besides the well recognized age and education effects, patterns of cognitive impairment are determined by the association between age and rurality as well as by vascular risk factors, with vascular dementia being more prevalent than in other European countries. On the whole cognitive impairment has the highest prevalence in rural elderly persons, with both vCIND and vascular dementia as predominant patterns. Inevitably the selection of contrasting socio-economical environments may generate a bias when generalizing for the whole Northern Portugal population disregarding the rural and urban counterparts, but is plainly justified as the project's aim was to uncover consequences of rural/urban disparities and socio-demographic inequities.

Further demonstration of variation in prevalence and incidence estimates and patterns of cognitive impairment according to educational/economical characteristics and vascular risk profile in Northern Portugal should be potentially helpful for estimating the "preventable fraction" of dementia in the community, since it is recognized that only a small fraction of CIND persons will progress to dementia over a short time span. Hopefully, the illiter- acy gap between urban and rural populations will soon fade away, but vascular risk factors need special attention from the Public Health Authorities, by adopting proactive early preventing measures.

\section{Competing interests}

The authors declare that they have no competing interests.

\section{Authors' contributions}

BN participated in the study design, acquisition and interpretation of data, drafting and revising the manuscript, RDS in data acquisition, analysis and drafting the manuscript, VTC in acquisition of data and revising the manuscript, JMR in revising the manuscript, JP in study design and data acquisition and MCS in study design, data analysis and interpretation and revising the manuscript. All authors read and approved the final manuscript.

\section{Acknowledgements}

This work was supported by grants of the Portuguese Society of Neurology and Janssen-Cilag Pharmaceutics, 2003 and Foundation Calouste Gulbenkian, 2005. The authors thank the team of psychologists involved in the field work and the general practitioners and nurses working in the Arouca and Sao João da Madeira health centres. A special thanks to the local populations, without whose collaboration this study would not be possible. The authors have no conflicts of interest with respect to this work.

\section{Author Details}

1 Serviço de Neurologia, Hospital Pedro Hispano, 4464-513 Senhora da Hora, Portugal, ${ }^{2}$ Centro de Estudos de Demências, 4100-440, Porto, Portugal, 3Serviço de Neurologia, Hospital de S.Sebastião, 4520-211 Santa Maria da Feira, Portugal, 4 Laboratório de Neuropsicologia, Hospital de S.Sebastião, 4520-211 Santa Maria da Feira, Portugal and 5UNIFAI, Instituto de Ciências Biomêdicas Abel Salazar (ICBAS), University of Porto, 4099-003, Porto, Portugal

Received: 30 December 2009 Accepted: 11 June 2010

Published: 11 June 2010

\section{References}

1. American Psychiatric Association: Diagnostic and statistical manual of mental disorders. Washington, DC. 4th edition. 1994.

2. Ebly EM, Hogan DB, Parhad IM: Cognitive impairment of the nondemented elderly. Arch Neurol 1995, 52:612-19.

3. Graham JE, Rockwood K, Beattie BL, Eastwood R, Gauthier S, Tuokko H, Mc Dowell I: Prevalence and severity of cognitive impairment with and without dementia in an elderly population. Lancet 1997, 349:1793-96.

4. Hofman A, Rocca WA, Brayne C, Breteler MM, Clarke M, Cooper B, Copeland JRM, Dartigues JF, Droux AS, Hagnell O, Heeren TJ, Engedal K, Jonker C, Lindesay J, Lobo A, Mann AH, Mölsä PK, Morgan K, O'Connor DW, Sulkava R, Kay DWK, Amaducci L, for the EURODEM prevalence research group: The prevalence of dementia in Europe: a collaborative study of 1980-1990 findings. Int J Epidemiol 1991, 20:736-748.

5. Garcia C, Costa C, Guerreiro M, Leitão O, de Mendonça A, Umbelino J: An estimate of the prevalence of dementia and Alzheimer's disease in Portugal. Acta Med Port 1994, 7:487-91.

6. Correia M, Silva MR, Matos I, Magalhães R, Lopes JC, Ferro JM, Silva MC Prospective Community-Based Study of Stroke in Northern Portugal. Incidence and case fatality in rural and urban populations. Stroke 2004 35:2048-2053

7. Correia M, Silva MR, Magalhães R, Guimarães L, Silva MC: Transient Ischemic Attacks in rural and urban Northern Portugal. Incidence and short-term prognosis. Stroke 2006, 37:50-55

8. Instituto Nacional de Saúde Dr. Ricardo Jorge/Instituto Nacional de Estatística: Fourth National Health Inquiry. Lisboa, Portugal. 2005

9. Viswanathan A, Rocca W, Tzourio C: Vascular risk factors and dementia. How to move forward? Neurology 2009, 72:368-374.

10. De Ronchi D, Palmer K, Pioggiosi P, Atti AR, Berardi D, Ferrari B, Dalmonte E, Fratiglioni $L$ : The combined effect of age, education, and stroke on dementia and cognitive impairment in the elderly. Dementia Geriatr Cogn Disord 2007, 24:266-73.

11. Purandare N, Burns A, Daly KJ, Hardicre J, Morris J, Macfarlane G, McCollum C: Cerebral emboli as a potential cause of Alzheimer's 
disease and vascular dementia: case-control study. BMJ 2006 332:1119-1124

12. Prins ND, van Dijk EJ, den Heijer T, Vermeer SE, Koudstaal PJ, Oudkerk M, Hofman A, Breteler MM: Cerebral white matter lesions and the risk of dementia. Arch Neurol 2004, 61:1531-1534.

13. Vermeer SE, Prins ND, den Heijer T, Hofman A, Koudstaal PJ, Breteler MM Silent brain infarcts and the risk of dementia and cognitive decline. NEngl J Med 2003, 348:1215-1222.

14. Paradise M, Cooper C, Livingston G: Systematic review of the effect of education on survival in Alzheimer's disease. Int Psychogeriatr 2009, 21(1):25-32.

15. Jorm AF, Dear KB, Burgess NM: Projections of future numbers of dementia cases in Australia with and without prevention. Aust NZJ Psychiatry 2005, 39:959-963.

16. Nunes B, Cruz VT, Pais J, Mateus A, Silva R, Silva MC: Rastreio populacional de demência e defeito cognitivo ligeiro nos concelhos de Matosinhos e de Arouca - populações e métodos do estudo piloto. Sinapse 2004, 4:26-33.

17. Galaria II, Casten RJ, Rovner BW: Development of a shorter version of the geriatric depression scale for visually impaired older patients. Int Psychogeriatr 2000, 12:435-443.

18. Ewing JA: Detecting alcoholism. The CAGE questionnaire. JAMA 1984 252:1905-1907.

19. Schmand B, Jonker C, Hooijer C, Lindeboom J: Subjective memory complaints may announce dementia. Neurology 1996, 46(1):121-125.

20. Blessed $\mathrm{G}$, Tomlinson BE, Roth M: The association between quantitative measures of dementia and of senile change in the cerebral grey matter of elderly subjects. Br J Psychiatry 1968, 114:797-811.

21. Folstein MF, Folstein SE, McHugh PR: "Mini-mental state". A practical method for grading the cognitive state of patients for the clinician. J Psychiatr Res 1975, 12:189-198.

22. Erkinjuntti T, Hokkanen L, Sulkava R, Palo J: The blessed dementia scale as a screening test for dementia. Int J Geriatr Psychiatr 1988, 4:267-273.

23. Reis A, Guerreiro M, Petersson KM: A sociodemographic and neuropsychological characterization of an illiterate population. App/ Neuropsychol 2003, 10:191-204.

24. Guerreiro M: Contributo da Neuropsicologia para o estudo das Demências. Phd thesis. Universidade de Lisboa, Faculdade de Medicina 1998

25. Newcombe RG: Two-sided confidence intervals for the single proportion: comparison of seven methods. Stat Med 1998, 17:857-872.

26. Bäckman L: Memory and cognition in preclinical dementia: what we know and what we do not know. Can J Psychiatry 2008, 53:354-60.

27. Fratiglioni $L$, DeRonchi $D$, Agüero-Torres H: World-wide prevalence and incidence of dementia. Drugs and Aging 1999, 15:365-375.

28. Fratiglioni L, Grut M, Forsell Y, Viitanen M, Grafström M, Holmen K, Ericsson K, Bäckman L, Ahlbom A, Winblad B: Prevalence of Alzheimer's disease and other dementias in an elderly urban population: relationship with age, sex, and education. Neurology 1991, 41:1886-1892.

29. Prencipe M, Casini AR, Ferretti C, Lattanzio MT, Fiorelli M, Culasso F: Prevalence of dementia in an elderly rural population: effects of age, sex, and education. J Neurol Neurosurg Psychiatry 1996, 60:628-633.

30. Cristina S, Nicolosi A, Hauser WA, Leite MLC, Gerosa E, Nappi G: The prevalence of dementia and cognitive deficit in a rural population of 2442 residents in northern Italy. A door-to-door survey. European J Neurology 2001, 8:595-600

31. Prencipe M, Santini M, Casini A, Pezzella F, Scaldaferri N, Culasso F: Prevalence of non-dementing cognitive disturbances and their association with vascular risk factors in an elderly population. J Neurol 2003, 250:907-912.

32. Ott A, Breteler M, Claus J, van der Cammen T, Grobbee D: Prevalence of Alzheimer's disease and vascular dementia: association with education. The Rotterdam study. BMJ 1995, 310:970-973.

33. Kokmen E, Beard CM, Offord KP, Kurland LT: Prevalence of medically diagnosed dementia in a defined United States population: Rochester, Minnesota, January 1, 1975. Neurology 1989, 39:73-76.

34. Harvey RJ, Skelton-Robinson M, Rossor MN: The prevalence and causes of dementia in people under the age of 65 years. J Neurol Neurosurg Psychiatry 2003, 74:1206-1209.

35. Rocca WA, Bonaiuto S, Lippi A, Luciani P, Turtú F, Cavarzeran F, Amaducc $L$ : Prevalence of clinically diagnosed Alzheimer's disease and other dementing disorders: a door-to-door survey in Appignano, Macerata Province, Italy. Neurology 1990, 40:626-631.

36. Vilalta-Franch J, López-Pousa S, Llinàs-Reglà : Prevalencia de demencias en una zona rural. Estudio de Girona. Rev Neurol 2000, 30:1026-1032.

37. Di Carlo A, Baldereschi M, Amaducci L, Maggi S, Grigoletto F, Scarlato G, Inzitari D: Cognitive impairment without dementia in older people: prevalence, vascular risk factors, impact on disability. The Italian Longitudinal Study on Aging. JAGS 2000, 48:775-782.

38. Rocca WA, Bonaiuto S, Lippi A, Luciani P, Turtú F, Cavarzeran F, Amaducc $L$ : Prevalence of clinically diagnosed Alzheimerï $i \frac{1}{2} 2$ disease and other dementing disorders: a door-to-door survey in Appignano, Macerata Province, Italy. Neurology 1990, 40:626-631.

39. Rocca WA, Hofman A, Brayne C, Breteler MMB, Clarke M, Copeland JR, Dartigues JF, Engedal K, Hagnell O, Heeren TJ, Jonker C, Lindesay J, Lobo A, Mann AH, Mölsä PK, Morgan K, O'Connor DW, Droux AS, Sulkava R, Kay DWK, Amaducci L, The EURODEM- Prevalence Research Group: Frequency and distribution of Alzheimer's disease in Europe: a collaborative study of 1980-1990 prevalence findings. Ann Neurol 1991, 30:381-390.

40. Rocca WA, Hofman A, Brayne C, Breteler MMB, Copeland JRM, Dartiques JF, Engedal K, Hagnell O, Heereen TJ, Jonker C, Lindesay J, Lobo A, Mann AH, Mölsä PK, Morgan K, O' Connor DW, da Silva Droux A, Sulkava R, Kay DWK, Amaducci L, The EURODEM- Prevalence Research Group: The prevalence of vascular dementia in Europe: facts and fragments from 1980-1990 studies. Ann Neurol 1991, 30:817-824.

41. Lobo A, Launer LJ, Fratiglioni L, Andersen K, Di Carlo A, Breteler MM, Copeland JR, Dartigues JF, Jagger C, Martinez-Lage J, Soininen H, Hofman A: Prevalence of dementia and major subtypes in Europe: $A$ collaborative study of population-based cohorts. Neurology 2000 54(Suppl 5):S4-59

42. Jorm AF: Cross-national comparisons of the occurrence of Alzheimer's disease and vascular dementia. Eur Arch Psychiatry Clin Neurosci 1991 240:218-222.

43. Ineichen B: Senile dementia in Japan: prevalence and response. Soc Sci Med 1996, 42:169-72.

44. Fish M, Bayer A, Gallacher JEJ, Bell T, Pickering J, Pedro S, Dunstan FD, BenShlomo Y, Ebrahim S: Prevalence and pattern of cognitive impairment in a community cohort of men in South Wales: metholology and findings from the Caerphilly Prospective Study. Neuroepidemiology 2008, 30:25-33.

45. Rockwood K, Wentzel C, Hachinski V, Hogan DB, MacKnight C, McDowell I, for the Vascular Cognitive Impairment Investigators of the Canadian Study of Health and Aging: Prevalence and outcomes of vascular cognitive impairment. Neurology 2000, 54:447-51.

46. Ferri CP, Prince M, Brayne C, Brodaty H, Fratiglioni L, Ganguli M, Hall K, Hasegawa K, Hendrie H, Huang Y, Jorm A, Mathers C, Menezes PR, Rimmer E, Scazufca M, for Alzheimer Disease International: Global prevalence of dementia: a Delphi consensus study. Lancet 2005, 366:2122-2127.

47. Kalaria RN, Maestre GE, Arizaga R, Friedland RP, Galasko D, Hall K, Luchsinger JA, Ogunniyi A, Perry EK, Potocnik F, Prince M, Stewart R, Wimo A, Zhang Z, Antuono P, for the World Federation of Neurology Dementia Research Group: Alzheimer's disease and vascular dementia in developing countries: prevalence, management, and risk factors. Lancet Neuro/ 2008, 7:812-826.

48. Letenneur L, Gilleron V, Commenges D, Helmer C, Orgogozo JM Dartigues JF: Are sex and educational level independent predictors od dementia and Alzheimer's diesease? Incidence data from the PAQUID project. J Neuro/ Neurosurg Psychiatry 1999, 66:177-183.

49. Matthews FE, Chatfield M, Freeman C, MCCracken C, Brayne C, MRC CFAS: Attrition and bias in the MRC cognitive function and ageing study: an epidemiological investigation. BMC Public Health 2004, 4:

\section{Pre-publication history}

The pre-publication history for this paper can be accessed here: http://www.biomedcentral.com/1471-2377/10/42/prepub

doi: 10.1186/1471-2377-10-42

Cite this article as: Nunes et al., Prevalence and pattern of cognitive impairment in rural and urban populations from Northern Portugal BMC Neurology $2010,10: 42$ 